\title{
On complacency, corporate cliffs and power distance: global leadership ethics from gender and cultural studies perspectives
}

\author{
Marco Tavanti \\ Associate Professor, School of Public Service, DePaul University, Chicago, USA \\ Patricia H. Werhane \\ Wicklander Professor of Business Ethics, Director, Institute for Business and Professional Ethics, DePaul \\ University and Ruffin Chair of Business Administration, Darden Graduate School of Business, University \\ of Virginia, USA
}

\begin{abstract}
Focusing on corporate leadership, this paper will discuss four factors that often thwart nondiscriminatory ethical leadership: complacency, the 'glass cliff' effect, the role of power distance relationships, and globalization. Complacency, the most prevalent, is probably the most obvious factor. The concepts of the 'glass cliff' - how women in leadership positions are associated with a higher risk of failure (Ryan and Haslam 2007) - and 'power distance' - the way power is perceived and distributed (Hofstede et al. 2010) both offer relevant perspectives to ethical leadership in the transforming environment of the twenty-first century. We will argue that three of these phenomena (and there are others) contribute to the perpetuation of gender inequality in leadership positions, and thus unfair distributions of power and influence that are not reflective of populations in the workplace nor in the community. It will turn out, however, that globalization actually can have a positive effect on improving gender distribution of leadership, so long as one recognizes what is needed to be an effective and ethical global leader.
\end{abstract}

Keywords: gender, women, leadership, glass cliff, corporate cliff, complacency, power distance, leadership ethics, cultural studies

To deny one's freedom or the equal rights of others bring into question one's self, since one's own freedom comes out of that of others. (Werhane 1996, p. 17)

\section{INTRODUCTION}

Part of the focus of ethical leadership is concerned with the moral and systemic issues connected to gender equality and diversity inclusion in organizational management and leadership positions and whether and how inclusions or exclusions are fair (Ciulla 1995; Ciulla et al. 2005; Werhane and Painter-Morland 2011). At the same time, in this age of globalization and the growth of what many call the 'Knowledge Era,' the idea of a 'good' (ethical and competent) leadership is dramatically changing. Society is no longer accepting a leader as merely an individual with charisma and knowledge and who leads or cajoles followers. Therefore, the demand for ethical leaders who are not merely part of a hierarchy is increasingly becoming a model for 'good' leadership. 
In commerce, despite the obvious fact that half the population of any community is female, the number of women in business leadership is scarcely increasing. According Fortune magazine, women hold 4.2 percent of Fortune 500 and Fortune 1000 CEO positions, but this number has only slightly increased in the last 10 years (Sellers 2012). Globally, the data is similar. According to a recent Grant Thornton study, globally women in senior management have increased only 2 percent from 19 percent to 21 percent since 2004 (Grant Thornton 2012) and a number of other studies have shown the systemic factors contributing to permanence and variations in the glass ceiling effects that lead to the exclusion of women from leadership positions (for example, Barreto et al. 2009; Bennett 2002).

Focusing on corporate leadership, in this paper we will discuss four factors: complacency, the 'glass cliff' effect, the role of power distance relationships, and globalization. Complacency, the most prevalent, is probably the most obvious factor. The concepts of the 'glass cliff' - how women in leadership positions are associated with a higher risk of failure (Ryan and Haslam 2007) - and 'power distance' - the way power is perceived and distributed (Hofstede et al. 2010) - both offer relevant perspectives to ethical leadership in the transforming environment of the twenty-first century. We will argue that three of these phenomena (and there are others) contribute to the perpetuation of gender inequality in leadership positions, and thus unfair distributions of power and influence that are not reflective of populations in the workplace nor in the community. It will turn out, however, that globalization actually can have a positive effect on improving fair gender distribution of leadership, so long as one recognizes what is needed to be an effective and ethical global leader.

\section{CHALLENGES TO ETHICAL LEADERSHIP}

\subsection{Complacency and social identity}

One of the gravest and most deeply rooted challenges to ethical leadership is complacency. Silence conquers courage when faced with unethical choices especially in the gender and cultural issues. Throughout history, acceptance of inequality in the workplace has been apparent; it has become second nature to the extent that distinguishing the difference between ethical and unethical choices seems impossible. Some people still today choose the comfort of the status quo over change, even when they acknowledge that there is something unfair about the paucity of women leaders in organizations. Furthermore, leaders often perpetuate this complacency by promoting people who look and act most like themselves (Rosener 1997). Thus, equal opportunities for women and minorities are thwarted even for the most talented.

A more nuanced version of this sort of complacency derives from social identity theory. According to these researchers, leaders are often chosen from 'the way[s] in which perceptions of leadership emerge as a result of the shared social identity of group members and the needs and interests that arise from requirements to enact that identity in different contexts. According to this analysis, a leader must be seen to epitomize what it means to be an ingroup member, and only a prototypical group member (i.e., one that maximizes both intragroup similarity and inter group differences ... is likely to be able to influence and lead the group' (Ryan and Haslam 2007, p. 552). Thus, according to this thesis, ingroups will be likely to choose or follow leaders who are part of, or seemingly cohesive with, that group. Since most companies today, both in the United States and globally, have male leaders, the ingroup that leader forms 
is likely to choose colleagues and successors who are similar to themselves. Thus diversity is truncated and male dominance in leadership positions continues unabated both in the United States and elsewhere. To counteract these tendencies, many of which are often implicit and not deliberate, in some European countries - such as Spain and France, for example - companies with more than 250 employees are required to have 40 percent women on their boards by 2015 (Grant Thornton 2012, p. 10).

Interestingly, according to Catalyst, a nongovernment organization that studies workplace diversity, when there are three or more women on the board of a company or in the executive suite, that company is more likely to have a diverse management. And, for those who think that diversity is simply a concept made up by human rights specialists, in those companies with at least three women leaders, the return on investment in those companies is up to 33 percent higher than in their non-diverse counterpart companies (Catalyst 2012). So complacency in any form not only thwarts equal opportunity but is costly as well.

\subsection{The glass cliff phenomenon}

A second phenomenon that confuses if not sidetracks ethical leadership is the 'glass cliff.' 'The glass cliff refers to [a practice wherein] women [are] more likely to rise to positions of organizational leadership in times of crisis than in times of success, and men [are] more likely to achieve those positions in prosperous times' (Bruckmüller and Branscombe 2010, p. 433). A glass cliff appointment is ordinarily a 'precarious leadership position in an organization in crisis' (Rink et al. 2012, p. 1306) and sometimes present in an organization that has been deemed hopeless by Wall Street or its financiers. Thus, the expression 'glass cliff' because the chances of rescuing this organization from bankruptcy or closure are slim at best, and therefore accepting such a position threatens one's status or reputation as a successful leader. Many believe that women are often put into these power positions not because of their corporate knowledge or their ability to complete a task, but because, it is alleged, women are gullible enough to accept leadership positions in times of crisis, where often men are not, and where sometimes their adversaries hope for failure. There is some evidence, although not conclusive, that more women than men are offered and accept glass cliff positions. And the results of these appointments are not always encouraging (Rink et al. 2012; Ryan and Haslam 2007). ${ }^{1}$ Let us look at two examples.

One example of the 'glass cliff' occurring in the workplace is the case of Kate Swann, appointed CEO of a British company, WH Smith (Ryan and Haslam 2005, p. 83). Ms Swann's duties at the time of her appointment were seen as impossible to accomplish - that is, to restore the company to its pristine condition. In the eyes of her employers, she was the perfect candidate to blame if the company's image was not restored. Ms Swann became CEO of WH Smith in 2003 while the company was rapidly losing market share, and job cuts and other difficult tasks were necessary 'to turn the company around and restore the retailer's fortunes' (Ryan and Haslam 2005, p. 83). While Ms Swann made a remarkable turnaround for the company, she took over at one of the toughest economic times in the company's history. In addition, the distinct leadership and management attributes in societies and sectors characterized by higher 'masculinity' dimensions (Hofstede et al. 2010, ch. 5), where gender roles

1. Rink et al. (2012) challenge the conclusion that glass cliffs are most often given to women, but their study comes from data collected from students and thus is less reliable than it should be. 
are clearly distinct and 'men are supposed to be assertive, tough, and focused on material success; women are supposed to be more modest, tender, and concerned with the quality of life' (ibid., p. 535) contributed to harsh judgments of women leaders making tough decisions.

A second example of the 'glass cliff' occurring in the workplace is demonstrated in a quote by Ms Marcegaglia, the first woman to lead Confindustria, 'the most important Italian major industries association' (Tavanti 2012, p. 295). While commenting on her own leadership as a woman, Ms Marcegaglia stated, 'It took them nearly 100 years to appoint a woman, and they chose the worst economic moment' (Tavanti 2012, p. 295). While not all women notice the injustice of premeditated promotions in the workforce, Ms Marcegaglia did. It is unfortunate that these schemes are accepted in today's society.

Interestingly, according to their recent study, Bruckmüller and Branscombe (2010) claim that, while studying women in crisis leadership positions is important, equally important is to study the fact that men are more likely to be appointed when there appears to be a greater chance for organizational success. So it may be that this is not pure discrimination. Rather, Bruckmüller and Branscombe contend, it is also possible that women are perceived as more capable of handling organizational crises while men are perceived as better at handling projects that appear likely to succeed. Again, these are stereotypes, but these stereotypes may have an effect in leadership choice (Bruckmüller and Branscombe 2010, for example p. 448). So choosing a woman in a glass cliff situation may not always be because of discrimination but rather, sometimes, because of her talents at handling tough situations.

According to Rink et al. (2012), social and financial resources also influence perceptions of glass cliff positions. From their study, they conclude that while both men and women consider financial and social resources when contemplating a glass cliff position, women worry more about the available social resources - that is, whether their peers and subordinates will accept them. Without that acceptance, women would be less likely to accept a precarious position. Men, on the others hand, according to this study, focused more on financial resources, without which they would be much less likely to accept a glass cliff position (ibid.). This evidence supports other studies that conclude that women tend to have a more collaborative rather than hierarchical leadership style (Rosener 1990; Werhane 2007b), so that for women social resources would be key to reversing a downward spiral in a precarious organization.

The 'glass cliff' phenomenon is evident in numerous companies; should it continue to be accepted? Are there not men capable of crisis management and women capable of managing successful companies? The problem is that stereotyping abilities from a gendered perspective is not only discriminatory but also obstructs the use of good talent in either situation. While inequality anywhere should be unacceptable, is there an alternate lens through which to look at this problem? One way to alter perceptions of the 'glass cliff' is for women to take this sort of promotion as an opportunity to change the culture of the workplace. By accepting leadership positions in difficult times and excelling in these trenches, one could change the culture at work and in society, as well as the mindsets of the men previously anticipating their demise. These actions could change the course of women in leadership all across the world. What women do in the United States could positively promote change in Italy, for example.

Women like Kate Swann accepted the challenge and blazed a new path for her future. Swann came into power at a difficult time, but against all odds she excelled where others could not. By the end of her term at WH Smith, she was seen as a legend. 
Now, as she moves on to her next endeavor, she is regarded as an excellent leader. Ms Swann was promoted at the wrong time, but she was determined to succeed against all odds.

What we can conclude from looking at glass cliffs is that women have the ability to lead organizations in a variety of situations. But we must avoid stereotyping them and also avoid stereotyping men. Women do not necessarily have this ability solely because they are women, but, according to a recent study of women leaders, they have this ability because they 'created a successful leadership style that worked well in diverse environments' (Werhane 2007b, p. 177). It is not gender that allows one to be a successful or non-successful leader, it is one's ability as an individual to be innovative and to ethically guide others. Women and men can do all of this and more, because of their abilities as human beings, not because of gender (Werhane 2007b).

\subsection{Power distance}

A third challenge to diverse ethical leadership is that of 'power distance.' This cultural dimension attempts to measure differences in the perception, acceptance, and expectations in social inequality and authoritarian relations in organizations. According to Hofstede et al. (2010, p. 532), power distance is 'the extent to which the less powerful members of institutions and organizations within a country expect and accept that power is distributed unequally'. Since all cultures are different, the acceptance of inequality varies from culture to culture. It is important also to understand that 'different cultures are apt to have different understandings of leadership' (House \& Global Leadership and Organizational Behavior Effectiveness Research Program 2004). While some may believe it is acceptable to have inequality in the workplace, other cultures see this as unimaginable. 'Status differences are universal, but cultures treat them differently' (Johnson 2011, p. 385).

An example of cultural persuasions on ethical leadership illustrating the concept of 'power distance' is connected to the Roman Catholic Church in Italy. 'The dominant presence of the Roman Catholic Church has deeply influenced Italian cultural values and its tolerance to unequal distribution of power commonly known as power distance' (House \& Global Leadership and Organizational Behavior Effectiveness Research Program 2004, p. 519). There has been, for hundreds of years, the acceptance of workplace inequality. 'Italians accept and somehow expect that some groups in society are more powerful than others. They act accordingly in their exercise of leadership and in the follower's acceptance of it' (Tavanti 2012, p. 290).

This brings to light a powerful aspect of cultural inequalities: the beliefs of the followers. Is it unethical if the followers, who are being discriminated, accept this discrimination as a way of life? The answer to this question entails wondering whether and how we should make moral judgments across cultures, and what the limits those judgments should be. Are cultures or countries autonomous, and should they be; or are there situations that require such judgments or even interventions? It is not the scope of this paper to answer that, but surely when there is genocide, rape, or systemic discrimination of one class, race or gender, such judgments are not without merit.

Focusing within the leadership models in the United States, various organizations have different leadership power structures. Most of the high technology companies in Silicon Valley, for example, have, by and large, flat leadership structures and a virtual absence of power distance. Other companies have more hierarchical, even dictatorial, leadership styles where followers are treated as such. The most famous example is Al Dunlap (often nicknamed 'Chainsaw Al'), who in the 1990s ruthlessly led first Scott 
Paper, then Kimberly Clark, and finally Sunbeam. In each case he fired thousands of workers and treated all employees with ruthless disrespect. Another famous 'dictator' CEO was Leona Helmsley, who in the 1990s ran Helmsley Hotels with an iron fist, treating her employees like servants and firing any employee who made even the smallest mistakes (Time 2010). These companies are also less likely to be diverse, as the Catalyst studies have shown.

Strong power distance relationships create a followership mentality that can be lethal both to a fair distribution of power and positions, and to corporate performance. The more general conclusion is that 'a community, any community, that fails to recognize persons as individuals as well as social beings with both individual rights and responsibilities for each other, is a community of less-than-persons who fail to recognize the core requirements of community and who they are as individuals' (Werhane 1996, p. 23).

\subsection{Globalization}

The fourth challenge of ethical leadership in the workplace is the dramatic growth of globalization (Robertson and White 2003). In the wake of building a more globalized world, there are many aspects that cross cultures and countries. Cultural and gender beliefs from one country tend to positively or negatively impact other countries around the world. In the past, there was a time when industrialized countries did not immediately impact each other. However, we are not separate any more. What one country believes on ethical leadership, in the sense of gender issues and cultural issues, will inadvertently spill over into other countries across the globe.

The complexity of increasingly globalized organizational structures and institutional frameworks requires a deeper look at unethical leadership practices. Leadership in global organizations requires both a systemic vision and a collaborative organizational dynamics model. There are a number of reasons why these two characteristics are important. First, in a global setting, leaders are faced with a wide variety of diverse political, social, and cultural challenges that cannot be dealt with merely by using management tools that are culturally biased or narrowly focused. Moreover, system-thinking is a prerequisite to ethical leadership since it demands that one not ignore, and indeed give fair attention to, diverse populations and cultural mores. As Uhl-Bien and others have argued, global leadership requires what they call 'complexity leadership' defined as 'a complex interactive dynamic - a network-based process in which a collective impetus for action and change emerges when heterogeneous agents interact in ways that produce new patterns of behavior or new modes of operating' (Uhl-Bien, et al. 2007, p. 110; see also Werhane 2007a).

Traditionally, leadership has been defined hierarchically as 'individuals who significantly influence the thoughts, behaviors, and/or feelings of others' (Gardner and Laskin 1995, p. 6). Given the complexity of leading in diverse cultures in much of the contemporary literature, ethical leadership, and in particular global leadership, are identified with transformational or collaborative leadership where there is not a simple hierarchical leader-follower dynamic. Rather, leaders think of themselves or are thought of as coaches partnering with their managers and employees in a collaborative effort to create value added, however it may be defined for that organization. 'In this model, leadership is an interactive, dynamic, and mutually interrelational process between leaders and managers, where each participant contributes to the vision and progresses toward change in the company. The most effective global leaders will be those who are not only visionary, but who are used to working with a diverse population collaboratively rather than in 
a traditional leadership-follower dynamic' (Werhane 2007a, p. 433). Interestingly, various studies have identified this style of leadership as predominantly a feminist style and most often demonstrated in women leaders.

If this analysis is correct, there should be - although we have not yet experienced it a growing demand for women leaders in global organizations. Similarly, since global leadership requires that one deal across cultures, race, religions, and ethnicities, a more diverse leadership team is best equipped for these operations. Thus ignoring women and minorities rather than placing them in leadership positions is both unfair and economically unsound logic if an organization is to succeed in a global environment.

\section{OVERCOMING ETHICAL LEADERSHIP CHALLENGES}

Many scholars believe we are capable of being transformed and having our minds altered for the betterment of society only if we are confronted with the existence, needs, and humanity of others. Taking a moment to examine the needs and desires of someone else as an equal human being can lead to better ethical practices and choices. Stated differently, 'How we define ourselves is clarified only when we confront other human beings as human beings' (Werhane 1996, p. 18). Whether we view others as equally important and valuable determines our capacity as ethical leaders. 'If each of us is pursuing his or her own interests without regard to others, there is little likelihood that we will honor promises or reciprocate except when it is in our selfinterest to do so' (ibid., p. 19). A way of changing the engrossing grip of inequality is by taking it upon oneself to change, and expecting one's followers to do the same. An ethical leader is someone who embodies her personal values, expects the same from those around her, and 'continually tests these values against social norms, organizational consistency, and outcomes' (Werhane 2007a, p. 433).

When dealing with cultures of different types it is best to keep an open mind, choosing to believe that one's own perspective is not always the right choice. Every culture and company can benefit from globalization and the cultural shifts that come with it by choosing to become more culturally aware, instead of fighting off the unknown.

These are lovely ideas but in the hard-core world of global commerce, sadly they are likely to be ignored. And thus, with some exceptions, questionable leadership practices may persist. However, let us step back and imagine we are part of this hard core, and as a bottom-line-focused corporate executive our objectives are to grow our markets and increase our return on investment in a variety global markets. But if this is the case, then both the Catalyst data on women leaders and the demand for complex leadership in global markets demonstrate the need for more diverse leadership. Thus a smart company and a visionary executive, merely keeping self-interest in mind, should seek and hire qualified women and minorities. Otherwise that executive will be cheating shareholders, and that too, is unethical.

\section{CONCLUSION}

Concepts like complacency, the 'glass cliff' and 'power distance' offer insights into defining models for discriminatory and otherwise unethical leadership. Ethical leadership is about those individuals in positions of authority who through collaborative leadership can improve workplace dynamics and organizational success by hiring qualified diverse managers. The advent of a global economy challenges companies 
to recalibrate their social identity and rethink their leadership models. More is expected of global leaders in the twenty-first century, and it is their duty to take the challenge and reformulate tired hierarchical male-dominated leadership agendas. Without adopting a new agenda that honors a diverse workforce and leadership team, no global company will be able to compete in world markets. It is society's duty to hold every leader accountable for their actions - not only their personal actions, but the actions and beliefs they bring into the workplace and to society.

\section{REFERENCES}

Barreto, M. da C., M.K. Ryan and M.T. Schmitt (2009), The Glass Ceiling in the 21st Century: Understanding Barriers to Gender Equality, Washington, DC: American Psychological Association.

Bennett, R.J. (2002), 'Cracking the Glass Ceiling: Factors Affecting Women's Advancement into Upper Management,' Academy of Management Executive, 16 (1), 157-159.

Bruckmüller, Susanne and R. Nyla Branscombe (2010), 'The Glass Cliff: When and Why Women are Selected as Leaders; in Crisis Contexts, British Journal of Social Psychology, 49 (3), 433-451.

Catalyst (2012), available at: http://www.catalyst.org/media/catalyst-study-reveals-financialperformance-higher-companies-more-women-top. Accessed February 2, 2013.

Ciulla, J.B. (1995), 'Leadership Ethics: Mapping the Territory,' Business Ethics Quarterly, 5 (1), 5-28, doi:10.2307/3857269.

Ciulla, J.B., T.L. Price and S.E. Murphy (2005), The Quest for Moral Leaders: Essays on Leadership Ethics, Cheltenham, UK and Northampton, MA: Edward Elgar.

Gardner, H. and E. Laskin (1995), Leading Minds, New York: Basic Books.

Grant Thornton (2012), 'Women in Senior Management: Still not Enough,' available at: http:// www.gti.org/files/ibr2012\%20-\%20women\%20in\%20senior\%20management\%20master.pdf.

Hofstede, G., G.J. Hofstede and M. Minkov (2010), Cultures and Organizations: Software of the Mind, 3rd edn, New York: McGraw-Hill.

House, R.J. \& Global Leadership and Organizational Behavior Effectiveness Research Program (2004), Culture, Leadership, and Organizations: The GLOBE Study of 62 Societies, Thousand Oaks, CA: Sage.

Johnson, Craig E. (2011), Meeting the Ethical Challenges of Leadership: Casting Light or Shadow, London: Sage.

Rink, Floor, Michelle Ryan and Janka Stoker (2012), 'Influence in Times of Crisis: How Social and Financial Resources Affect Men's and Women's Evaluations of Glass-Cliff Positions,' Psychological Science, 23 (11), 1306-1313.

Robertson, R. and K.E. White (2003), Globalization: Analytical Perspectives, New York and London: Taylor \& Francis.

Rosener, J. (1990), 'Ways Women Lead,' Harvard Business Review, November-December, $119-125$.

Rosener, J.B. (1997), America's Competitive Secret: Women Managers, New York: Oxford University Press.

Ryan, M. and S.A. Haslam (2005), 'The Glass Cliff: Evidence that Women are Over-Represented in Precarious Leadership Positions,' British Journal of Management, 16 (2), 81-90.

Ryan, M.K. and S.A. Haslam (2007), 'The Glass Cliff: Exploring the Dynamics Surrounding the Appointment of Women to Precarious Leadership Positions,' The Academy of Management Review, 32 (2), 549-572, doi:10.2307/20159315.

Sellers, P. (2012), 'Fortune 500 Women CEOs Hit a Milestone,' CNNMoney, November 12. Retrieved from: http://postcards.blogs.fortune.cnn.com/2012/11/12/fortune-500-women-ceos-3/.

Tavanti, M. (2012), 'The Cultural Dimensions of Italian Leadership: Power Distance, Uncertainty Avoidance and Masculinity from an American Perspective,' Leadership, 8 (3), 287-301, doi:10.1177/1742715012441876. 
30 Leadership and the Humanities, Vol. 1 No. 1

Time (2010), 'Top 10 Worst Bosses,' October 18. Available at: www.time.com/time/specials/ packages/article/0,28804,2025898_2025900_2025888,00.html. Accessed February 4, 2013.

Uhl-Bien, Mary, Russ Marion and Bill McKelvey (2007), 'Complexity Leadership Theory: Shifting Leadership from the Industrial Age to the Knowledge Era,' Leadership Quarterly, 18 (4), 298-318.

Werhane, Patricia H. (1996), 'Community and Individuality,' New Literary History, 27 (1), 15-24.

Werhane, Patricia Hogue and M. Painter-Morland (2011), Leadership, Gender, and Organization, Dordrecht and London: Springer.

Werhane, Patricia H. (2007a), 'Women Leaders in a Globalized World,' Journal of Business Ethics, 74 (4), 425-435.

Werhane, Patricia H., Margaret Posig, Lisa Gundry, Laurel Ofstein and Elizabeth Powell (2007b), Women in Business, Westport, CT: Praeger. 